\title{
Studies About How E-Commerce Logistics Can Reduce Operational Costs
}

\author{
Bao Jianmei \\ School of Economic and Management \\ Shenyang Aerospace University \\ Shenyang, China
}

\author{
Liu Chang \\ School of Economic and Management \\ Shenyang Aerospace University \\ Shenyang, China
}

\begin{abstract}
This paper is the analysis of electronic commerce development process, the logistics cost composition and characteristics, and the content of our country sheds cost and how characteristic. To our country electronic commerce development environment, the factors which influence the logistics cost. Through the analysis of their impact factors, how to use scientific methods to control logistics costs. The electronic commerce to the advanced experience of foreign countries and the level which should draw lessons from, to speed up our country electronic commerce logistics industry development. The logistics in e-commerce development process played an irreplaceable role, both inseparable relationship promote mutually, common development, for the future of e-commerce to a more simple, fast, perfect, healthy way to lay a solid foundation.
\end{abstract} Cost

Keywords- Electronic Commerce; Logistics; Operation

\section{INTRODUCTION}

The advent of the Internet era, to accelerate the development of the logistics industry. To China's logistics industry has brought new development opportunities and space. In twentieth Century, electronic commerce of the informationization, the network product, because of its convenient, fast, safe, caused the wide attention of people. The emergence of electronic commerce, has not only changed the traditional business model, but also to the fusion between industry and the adjustment of the economic structure of a positive impact. With the development of electronic commerce, more and more traditional enterprises begin to explore the field of electronic commerce. It has been recognized, the logistics has become the electronic commerce is carried out smoothly and a key factor in development. If there is no efficient, fair, smooth logistics system, the advantages of e-commerce can hardly be effective development. But today in twenty-first Century, with a minimum of input to obtain the greatest return is each company, each industry can not replace the economic ideas. So how to ensure electronic commerce logistics efficiency, expedite premise, reduce its operation cost has become a crucial problem.

With the rise of enterprise e-commerce, the logistics distribution is increasingly becoming the focus of most concern. The rapid development of e-commerce and the lagging situation of logistics distribution system have become inevitable problems. The efficiency of the logistics distribution system is the key to the success of e-commerce; to break through the logistics bottlenecks in the development of e-commerce, the top priority is to establish a social, industrial and modern logistics distribution system with high-efficiency and rationalization as soon as possible. Based on the modern communication, especially on the basis of Internet, E-commerce logistics cost applies modern information technology for the planning, organization, command, coordination, control and decision-making of logistics cost. Logistics target cost control is to find the discrepancy with the target cost timely in the process of cost formation, based on the guidance, restriction and supervision, take corrective measures, use the methods of value engineering and cost analysis, improve the logistics process and distribution logistics service mode, and guarantee the realization of target cost. The meaning of logistics cost management is that through the effective grasp of logistics cost, using benefits antinomy relation between the factors of logistics, organizing scientific and reasonable logistics activities, strengthening the effective control of costs in the process of logistics activities, reducing the consumption of materialized labor and living labor in the logistics activities so as to reduce the total logistics cost and improve economic efficiency of enterprises and society.

\section{LOGISTICS COST OF E-COMMERCE}

\section{A. Meaning of logistics cost}

Logistics cost refers to the monetary expression of all kinds of labor and materialized labor consumed in the process of spatial displacement (including static state). Specifically, it is the sum of labor, financial resources and material resources consumed in various activities of product physical movement process.

\section{B. The composition of e-business logistics costs}

E-commerce logistics costs can be divided into direct logistics costs and indirect logistics costs, as shown in the figure below 


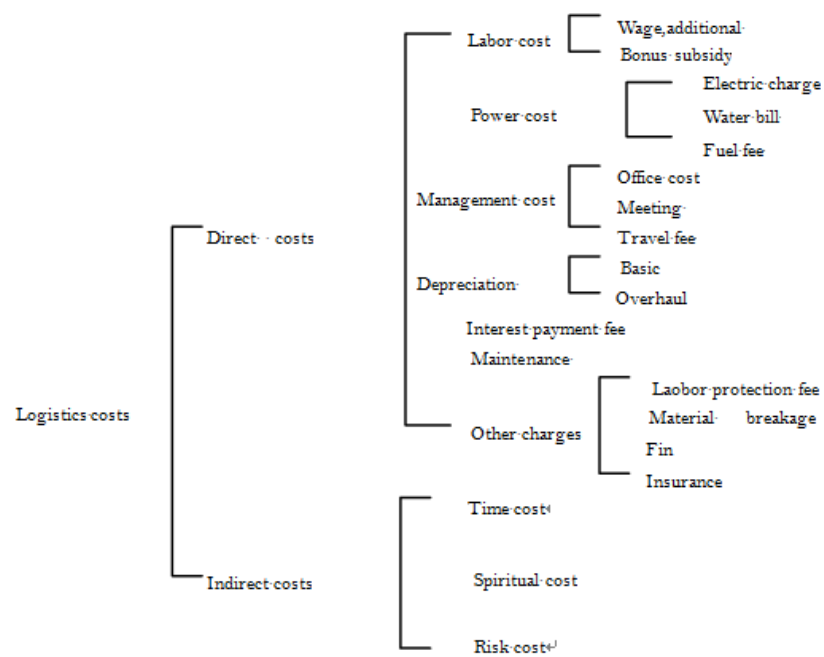

Figure 1. Classification chart of logistics cost

\section{THE ANALYSIS OF AFFECTING LOGISTICS COSTS}

\section{A. Factors of affecting logistics costs}

Many factors affect the logistics cost and the main three factors are: competitive factor, product factor, space factor.

\section{1) Competitive factor}

Market environment is unpredictable, and full of fierce competition. In such a complicated market environment, enterprises respond to competition at the cost of improving logistics cost.

\section{2) Product factor}

a) The types of the products

According to statistics, the percentage of logistics cost in the sales of different product classification (chemical products, wood, including furniture, textile, petrochemical and plastic products, rubber products, metal products, food and consumer goods)

\section{b) The density of the products}

Product density also has an impact on logistics costs because the density of the products is determined by its weight and volume. And the product transportation costs.

\section{c) The value of the products}

The value of the products is different, so the support of the logistics cost is different. Although the costs of transportation and warehousing are typically calculated on the weight and volume, logistics costs of high-value products are relatively higher than general products.

\section{3) The space factor}

Service-- in terms of customer service, avoid the problems of stock-out, goods damage, missing package, and low costs;

Speed--deliver the goods to the appointed place and within the time specified quickly as the user said;

Space saving--land cost is lower in our country, but it will keep on rising. The effective use of urban area should be fully considered; stereo facilities and related logistics machinery should be gradually developed so as to make effective use of space;

Stock control-- more storage places are needed if the inventory is too much, and too much inventory can lead to overstocked funds and waste. Therefore, the inventory must be controlled in accordance with the change in demand of production and circulation.

\section{B. Approach to E-commerce logistics cost analysis}

Approach to logistics cost management analysis must be well grasped for the accurate logistics cost management, and the following methods are used commonly.

1) Comparative analysis

The horizontal comparison: Calculate respectively all the enterprise logistics costs including the cost from supply logistics, production logistics, distribution logistics, return logistics and waste material logistics (sometimes including circulation processing and distribution), then find the part with highest logistics cost through horizontal comparison.

The vertical comparison: compare all the previous logistics costs with the logistics costs in this year, analyze the reason and part of the logistics costs increase or correct immediately if the increased logistics costs are ineffective;

The plan and actual comparison: compare the actual logistics costs of the year with the original budget, analyze the reason and part if it's overspent. This can grasp the problems and weak links of enterprise logistics management.

\section{2) Exclusion}

There is a method called Activity Based Management in the logistics cost management. One of the approaches is to divide the logistics related activities into two kinds: one is value added activities, such as in-out warehouse, packing, loading and unloading, which is directly related with the owner; another is non-value-added activities, such as meeting, change process and maintenance of mechanical equipment, which have no direct relationship with the owner.

\section{Experience of logistics costs management in US}

The logistics cost accounts for about 10\% of GDP in US, according to the unique analyses of costing method. The logistics costs in the United States are mainly composed of three parts: the inventory costs, the transport costs and the management cost.

Improve efficiency by reduce logistics cost; reducing inventory costs is the main source of decreasing logistics costs. The concept of logistics cost must be expanded.

\section{APPROACH TO DECREASE THE E-COMMERCE LOGISTICS COST}

\section{A. Establishing structure of modern enterprise logistics organization}

To solve the problems of divergent functions of enterprise internal logistics and difficult coordination fundamentally, we must start from the transformation of organization structure of enterprises and establish modern enterprise logistics organization structures. At present, there are mainly several enterprises' logistics organization structures for choosing:

First, the traditional organization structure model. Basically, based on the traditional functions of specialization, set branch according to the function; the logistics activity is actually scattered in various relevant professional activities, coordinated by the upstream authorities. 
Second, set of function organization structure. On the basis of the tradition, integrate the logistics functions within the various professional departments; highlight the logistics activity in the organization, so as to be convenient for planning, control, and coordination of all departments.

Third, the independent function of organization structure. Separate the core functions of material distribution and material management, and establish professional sector equal with the department of finance, manufacturing, and marketing.

Fourth, the integration of organizational structure. Integration mainly features: Each area is combined to build into a separate linear operation unit. Due to the welldefinition of duty field operated, as an operation unit, the support for manufacturing and support for purchasing and material distribution is treated the same.

\section{B. Construct high-efficiency logistics system}

According to logistics cost trade-off theory, the key to reduce the logistics cost lies in the overall consideration of logistics rather than the one-sided emphasis on certain aspects. In other words, put all aspects of logistics as a logistics system for overall design and management, give full play to its system functions and efficiency with best structure and cooperation, and achieve the overall logistics rationalization. Logistics system includes all activities related to logistics, such as commodity supplemental, warehousing, storage, inventory management, logistics operations, shipping, distribution, and information management. Obviously, for improving the quality of logistics, accelerate the speed of logistics, reduce logistics costs and reduce unnecessary waste and loss, thereby building enterprise logistics system and operating efficiently are essential in reducing logistics costs throughout the enterprise.

Certainly, the high-efficiency operation of the logistics system must also have the support of information system. Enterprise logistics can be truly efficient and operated with high speed only on the basis of comprehensive information and rapid sharing. It' $s$ not static after the establishment of the logistics system; we must often re-evaluate and improve the system in order to continuously improve the efficiency of the system, that is, the plan filing, implementation, and performance checks. Start from the point of view," whether system can function very well" and "whether activity efficiency and accuracy can be further improved", analyze and improve through a variety of evaluation criteria. Establish better systems through these revaluations. In addition, changes in market trends bring changes in customer demand; changes of transportation infrastructure construction and other environment will also affect the logistics system, so logistics system must therefore be re-constructed in time.

\section{Logistics management of innovative business}

Logistics management innovation is to use modern logistics concepts and advanced logistics technology for effective control, supervision and improvement of enterprise logistics activities according to the actual situation, in order to achieve the goal of improving logistics efficiency, and reducing logistics costs. Adopt new logistics management method. Introduction of activity management is to treat logistics activity as a collection of a series of activities, try to eliminate all unnecessary operations and reduce operating cost. Activity management exists in all aspects of enterprise logistics management process. The key lies in activity system design, timely activity and activity quality control. Different logistics operating system design, with different desired activities and different consumptions, and logistics costs are caused by the activities of the logistics. In general, $60 \%-80 \%$ of the costs of logistics operations are identified in system design phase, the potential for cost reduction is little once the system is put into operation. The costs of logistics activities are incurred in the process, but have its roots in the logistics system design. For logistics cost management, the early factors affecting logistics system design can gain real competitive advantage.

Enterprise logistics outsourcing (using third party logistics)

Enterprises, especially small and medium-sized enterprises, has no need to build subsidiary corporation of logistics, which is not to say that independence of the enterprise logistics activity is impracticable; enterprise can control the logistics cost by outsourcing it to the third party logistics enterprise(social professional logistics companies). A large number of professional logistics companies appear as the social division of labor becomes more and more refined. These professional logistics companies have professional logistics technology and management methods and fully concentrate on logistics management as logistics is the enterprise's core business. The external professional logistics companies can perform all or part of the enterprise logistics management function, whose scope can be traditional transportation or warehousing services, and also be the whole logistics businesses. On the one hand, entrusted logistics outsourcing can make the enterprise get rid of the complex logistics business, focus on developing their own core business, and enhance the consistency of strategic actions; on the other hand, entrusting a specialized logistics company can make full use of its advantages of professional staff and technology, which makes the enterprise logistics management more standardized, economical and cost-saving of the logistics

\section{CONCLUSION}

Under the e-commerce environment, the development of e-commerce promotes the rapid rise of modern logistics industry greatly, and the logistics can also improve the efficiency and effectiveness of the electronic commerce, coordinate the goal of e-commerce, expand the market area of e-commerce, realize the integration of supply chain based on e-commerce, integrate the trade flow, information flow and cash flow of e-commerce, consequently prompts the e-commerce to be the most competitive business form in next century.

The rapid development of electronic commerce puts forward higher and more pressing requirements to the traditional logistics enterprises in our country; the transformation from the traditional transportation and storage enterprises to modern logistics enterprises is imperative. So, establish basic logistics platform system and e-commerce distribution service system with more energy while focusing on the electronic commerce, gradually improve our country's logistics platform and set up modern logistics industry. China has just stepped from 
a seller's market into a buyer's market; we can cross the primary stage of logistics development in developed countries through learning and communication, and enter the fast track of logistics development by taking advantage of the information technology and network technology almost synchronous with the world, and through drawing lessons from the advanced technology of foreign logistics development.

\section{REFERENCES}

[1] Wang Hang. Study on the return goods logistics service and logistics cost under B2C e-commerce environment. [M] 2010(12)

[2] Zheng Jinhua. Development of our logistics enterprises under ecommerce environment [J]. 2011, (1)
[3] Guo Xiaoli. Research on the existing problems of current ecommerce logistics development in enterprises [J]. Market Modernization 2010, (29)

[4] Lv Linli. Selection and cooperation of supplier in the mode of supply chain management 2009, (05)

[5] Liu Tianxiong Cost management in network age [J]. Journal of Changsha electric power institute 2008, (01)

[6] Wang Ying Logistics costs control based on purchase analysis [J] China logistics and purchasing 2008 (09)

[7] Zhang Yunting. The application of value chain theory in enterprise management [J] Economic Herald 2008(03)

[8] Kang Shanzhao, Discussion of development and operation mode in Chinese e-commerce logistics

[9] John Mangan, Chandra Lalwani, Tim Butcher. Global Logistics and Supply Chain Management [M]. Publisher: Wiley, June 2008 